\title{
THE IMPORTANCE OF THE STUDY OF BIOCHEMISTRY.
}

BY E. A. DE SCHWEINITz, WASHINGTON, D. C.

WHEN the controversy between the two schools of the vitalists and chemists as to the true cause of the diseases produced in animals by the inoculation of putrefactive organic matter was at its height, Panum, of Denmark, made some careful researches and extracted from putrid organic matter chemical substances, which, when perfectly free from every form of germ life, produced intoxication and death. But, he said the poison extracted from this putrid matter is undoubtedly a pure chemical compound, it may, however, be produced by a microbe, and both microbe and poison play their part in the disease.

Now more than fifty years later, though the microbian origin of most diseases has been thoroughly established, it has also been shown that the chemical products of these germs are the direct cause, in most instances, of the fatal effects. For example, in diphtheria the growth of the germ is but a local manifestation, while the poison it produces is distributed through the whole system. When, however, the germ has been discovered that is responsible for a disease or for other changes, to which we will presently refer, the door has but been opened for a study of the most interesting chemical problems that can be imagined. Gernas in general are cells of protoplasm, and it is by a study of their actions and the changes which they produce that we can gain a better insight into the processes of life. Fortunately the majority of germs can be easily cultivated artificially, so that it is not difficult to obtain solutions of their products, but it is difficult to isolate these products from the solution and determine their nature. For the most part the substances produced by bacterial growth have been found to belong to two classes, the albuminoids and ptomaines, the latter corresponding closely in many of their properties and composition to the vegetable alkaloids. Our knowledge of the albuminoids, however, is very meager. We can divide them into certain general classes as $I$, globulins; 2, albumoses (hemi-proteo or deutero albumoses), ; 3, alkali or acid albumen; 4, peptones, etc.; but with this we have only made a step in the dark as it has given no idea of the actual

1 Read at the Baltimore neeting, December 28,1893 . 
composition of the substances about which we speak, beyond that they contain carbon, hydrogen, oxygen, nitrogen, and sulphur, and phosphorus in certain proportions, and differ in coagulation. Do these apparent albuminoid substances from bacteria belong to the class of albumoses, or are they chemical disastases or ferments, many of the reactions of which they show? Can they be proved to be diastases by their hydrating and digesting action and shown to be allied to ptyalin, pepsin, etc.? At first it was held, and is still held by some, that the presence of albuminoid matter was necessary to the growth of the germ and that the products of the germ life were changes or simply decomposition products of the albuminoid matter upon which they fed. But it has been proven too that some of the same substances are obtained by the simple action of acids and alkalies upon albuminoids, and it is often difficult to decide whether the albumoses and alkaloids have been produced by the germs or by the alkali or acid. To decide this it is necessary to cultivate the germs upon solutions which do not contain a trace of albuminoid matter. This Fermi and Uschinsky have succeeded in doing with a number of different germs upon a solution of glycerine and mineral salts (ammonium phosphate, and acid potassium phosphate), and I have also with the hog cholera, glanders, and recently tubercle bacillus by the addition of asparagine to the above liquid. From these cultures albuminoid substances have been obtained as well as alkaloids, showing that they have truly been built up and elaborated by the germ and are to be compared to intercellular secretions and excretions of these minute forms of life, and not to simple products of decomposition from albuminoid matter in solution. That the products formed under the different conditions are similar is shown by the same physiological action of mallein prepared from these artificial cultures or from cultures upon beef broth. This power of the germ to multiply upon a solution of mineral salts where the carbon, hydrogen, nitrogen, and phosphorus are present in an easily assimilable form is not surprising, for we deal here with the lowest form of vegetable life, and it is well known that plants cannot live upon albuminoid matter directly, but only when by decomposition it has been reduced to its elementary condition. 
The study of these products of the germ life has made but little progress so far as their actual chemical constitution is concerned. Much more attention has been paid to their physiological effect. It has been learned that some of these products will render an animal insusceptible to the action of disease germs, but what the chemical change which can have taken place and caused this immunity may be, is one of the problems for the biochemist and physiologist to decide.

It has been found too that the blood serum of animals that have been made immune to disease has a germicidal action and will render other animals immune. Where does this property lie? What chemical change again has the blood undergone?

In his studies upon the albuminoids of the egg, Scholl has indicated where this property may be. He found that egg albumen exerted a germicidal effect, that this germicidal power was destroyed by heat and could be restored by treating the albumen with alkali. This was similar to some of Buchner's observations upon blood serum, where he found the bactericidal property could be restored by the use of an alkali. Scholl's theory for explaining this, and also at the same time the coagulation of albumen, is that the normal albumen has a composition corresponding to a bicarbonate, that upon heating, carbon dioxide is given off and the albumen coagulated by the consolidation of two molecules, while when the alkali albumen is heated no decomposition will take place or coagulation of the albumen.
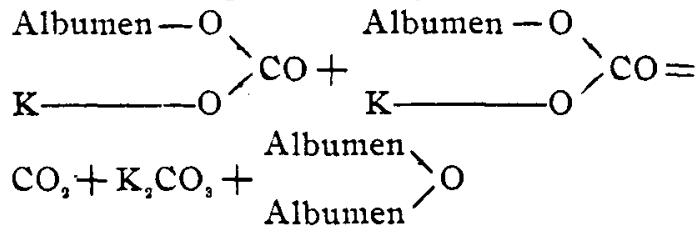

While $\mathrm{K}-\mathrm{O} / \mathrm{CO}+2 \mathrm{KOH}=\mathrm{K}_{2} \mathrm{CO}_{3}$

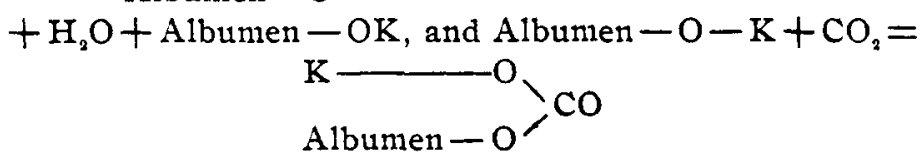

The carbon dioxide in the albumen is also set free by acid in the 
cold which will explain the coagulation of albumen by acid. In the albumen molecule then, there is a group of atoms with a bactericidal action, which grouping is destroyed by heat and restored by alkali, just as there are certain groupings necessary for the production of a disinfectant, or rather just as the disinfectants are characterized by certain groups. The confirmation of these experiments will open up a field of enormous possibilitics, as sulphur is an element which in many cases can replace oxygen, and the resulting compounds would be rery interesting, as well as lead to a number of new products and eventually to a better understanding of the albuminoid molecule.

As just mentioned, it has been found that in the case of a great many diseases, animals can be made insusceptible by raccination. and that the blood of such immune animais will make otlers inmune. But this immunity only holds for the particular disease against which the animal was first raccinated, and cloes not protect the animal against another disease. A guinea pig can be protected from a hog cholera inoculation by an injection of the albuminoid product extracted from the cultures. The same pig will die if inoctlated with swine plague. If, howerer, it be vaccinated both for hog cholera and swine plague, with the products extracted from their respective cultures, the animal will be insusceptible to both diseases. Just in the same way in each particular disease some chemical change is produced in the blood or tissues and the work of the chemist should be to find out what these changes are. The possibilities are enormons, the difficulties many, but by careful stucly accompanied necessarily with a certain anount of bacteriological work and the olservation of pathological changes, we can hope to arrive at a more definite understanding of the process of life.

It is, however, not only with reference to diseases that a study of biochemistry is inportant. Firom a practical and commercial stanclpoint the work is useful. J. A. Davalos, of Hayana. describes the isolation of a clistinct ferment and a number of bacilli from different tobacco leaves. some of which in artificial culture give distinct poisons. The different varieties of tobacco show different germs. These germs, by their growth upon the

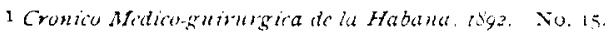


tobacco, give to it its peculiar flavor and odor, and the different qualities of tobacco owe their value to some particular ferment. As I have noticed, a bright yellow American high grade tobacco shows the presence of a germ altogether different, producing different substances from that of a low grade tobacco. Therefore, if the germs of a low grade tobacco can be destroyed and those from a fine tobacco substituted, we should be able to greatly improve the manufactured article. Now in practice, before the fermentation, some good tobacco is often mixed with the poorer grades to improve the quality. The manufacturer has learned by experience to make use of the different germs of the tobacco. But the chemist should not stop here. He should find out what the products of the growth of these germs are. This is possible because the germs can be isolated, cultivated, and the product of each individual germ determined, and eventually its identification or synthetic preparation.

Again, in Denmark, the practical manufacture of butter and cheese has been greatly advanced by the use of butter ferments, as they have been called. The flavor and aroma of butter and cheese are due to the products of a particular bacterium, or of several. Now these can and have been isolated, and to produce the best butter and cheese only those bacteria are used upon sterilized milk which give a desirable flavor, while normally those with undesirable products would also be present and interfere with the character of the butter and cheese. Here again the products of the growth of these bacteria should be studied, which in many instances would no doubt be found to be substances of easy synthetic preparation. It would be very much better to be able to add to a butter or cheese some particular extract which will impart the special flavor, rather than to have to inoculate the cheese and milk with a particular bacterium or mixture of bacteria for a desired quality. As has been well stated, we may see the time when each dairy is provided with a bacteria farm, and each particular brand of butter and cheese will have its corresponding originator, labeled and reared with as much care as is given to the cow from which the milk is obtained.

In their relation to the soil and plant life the germs and their 
products are invaluable. Warrington and Winogradsky, in their isolation of the nitrifying organisms which convert nitrogenous matter into nitrites and nitrates, have thrown great light on the absorption of nitrogen by plants. Recently Winogradsky has described an organism which converts the nitrogen of the air directly into nitrates. Again, there are a number of germs that are ordinarily found in water or the soil which will reduce nitrates to nitrites or ammonia, as well as some pathogenic germs usually present in the soil which will flourish in artificial media in an atmosphere of nitrogen. We know that a subsoil, freshly turned, will not be productive until it has been exposed for some length of time to the air and moisture and to the action of the germs of the air. The plant does not take up directly in the form in which it exists in the soils, the mineral matter that it needs for its growth, but only when that is modified to a simpler form can it be utilized. Phosphorus is one of the elements which, whether combined in albuminoids or mineral salts, seems to be necessary for the growth of the germ, and is also necessary for the life of plants. By closely following the gradual changes in the artificial cultures of germs, we can arrive at a more definite understanding of the assimilation of mineral matter by the plant, as well as the fixation of carbon, the formation of starch and sugar, and possibly also, as has been suggested, of the building up of alkaloids.

I have only mentioned a few of the many directions in which a conjoint study of bacteria and their products are important with the desire of emphasizing the interest attaching to such investigations. It is along this line of research that the solution of many of the problems of life that have been a puzzle to both physiologist and chemist nudoubtedly lies.

\section{DETERMINATION OF THE CRYSTALLIZABLE SUGAR IN THE BEET.}

BY H. PELLET.

TRANSLATED AND AJstracted BY G. L. SPENCER, Washington, D. C

$\prod \begin{gathered}\text { HIS is an extensive article including a résume of practically } \\ \text { all that has been written by the leading authorities upon }\end{gathered}$ I Read before the World's Congress of Chemists, August 22, I 893 